Harvard Kennedy School Misinformation Review ${ }^{1}$

September 2020, Volume 1, Special Issue on COVID-19 and Misinformation

Creative Commons Attribution 4.0 International (CC BY 4.0)

Reprints and permissions: misinforeview@hks.harvard.edu

DOI: https://doi.org/10.37016/mr-2020-39

Website: misinforeview.hks.harvard.edu

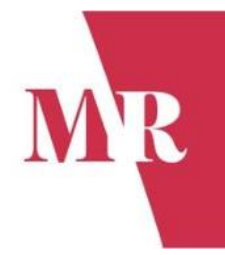

\title{
Anger contributes to the spread of COVID-19 misinformation
}

A survey conducted over South Korean adults $(N=513)$ reveals that emotions, specifically anger, contribute to the broader spread of misinformation on COVID-19 by leading angry individuals to consider false claims to be "scientifically credible." This pattern is more evident among conservatives than liberals. Our finding sheds light on new measures and journalistic interventions that could alleviate the public's anger and foster science-based conversations during a public health crisis.

Authors: Jiyoung Han (1), Meeyoung Cha (2), Wonjae Lee (3)

Affiliations: (1) School of Computing, Korea Advanced Institute of Science and Technology (KAIST), Republic of Korea, (2) Data Science Group, Institute for Basic Science (IBS), Republic of Korea, (3) Graduate School of Culture Technology, Korea Advanced Institute of Science and Technology (KAIST), Republic of Korea

How to cite: Han, J., Cha, M., \& Lee, W. (2020). Emotion and misinformation in times of public health crisis. Harvard Kennedy School (HKS) Misinformation Review, 1(3).

Received: June $8^{\text {th }}, 2020$. Accepted: August 28 ${ }^{\text {th }}, 2020$. Published: September $17^{\text {th }}, 2020$.

\section{Research questions}

- What are the roles of negative emotions, such as anger and fear, in the spread of misinformation about COVID-19?

- What is the cognitive mechanism that motivates people to share false claims about COVID-19?

- Are these roles of negative emotions on the spread of falsehoods different as a function of political ideology?

\section{Essay summary}

- South Korea is among the first countries to hold a general election amid the COVID-19 pandemic. Although emotional arousal during an election is nothing new (Marcus, Neuman, \& McKuen 2000 ), this one is special. The imminent threat to the public health escalated fear and anger in the Korean mass public (Kang, 2020); these negative emotions also likely fueled the broader and faster spread of misinformation (Vosoughi, Roy, \& Aral, 2018). This paper thus analyzes people's beliefs toward misinformation in times of a public health crisis and explains the role of emotion in diffusing false claims about COVID-19 in South Korea.

- Prior research found that right-leaning individuals have a lower threshold for experiencing

\footnotetext{
${ }^{1}$ A publication of the Shorenstein Center for Media, Politics and Public Policy, at Harvard University, John F. Kennedy School of Government.
} 
negative emotions than left-leaning individuals (Skitka, Bauman, Aramovich, \& Morgan, 2006). Building on this literature, we investigate whether the impact of fear and anger during this "infodemic" varies along ideological lines.

- We fielded an online survey with 513 South Korean adults in the run-up to the 2020 South Korean legislative election (April 9th to $13^{\text {th }}, 2020$ ). Our findings confirm that those expressing a higher level of anger were more likely to disseminate misinformation about COVID-19. Such individuals considered the falsehoods, mainly about bogus cures, to be "scientifically credible."

- Moreover, this belief tendency was stronger among conservatives than liberals. The observed effect was persistent after controlling for party identification, gender, age, region, education level, and household income.

\section{Implications}

\section{Anger fuels the COVID-19 misinformation}

Studies have found profound behavioral differences associated with emotions: Fear is connected to "behavior reconsideration," whereas anger to "strong action tendencies" (Groenendyk \& Banks, 2014; Lerner et al., 2003; Lerner \& Keltner, 2001; Miller et al., 2009; Valentino et al., 2015; for a review, see Carver \& Harmon-Jones, 2009; Lerner \& Keltner, 2000; Smith \& Ellsworth, 1985).

Before acting on a claim, anxious individuals are prone to wait and search for information to verify whether the claim is right or wrong (MacKuen et al., 2010; Turner et al., 2006; Valentino et al., 2008; see de los Santos \& Nabi, 2019; Zhao \& Cai, 2009 for counter-evidence). To make accurate judgments, anxious individuals tend to seek and learn related information with open minds.

On the other hand, angry individuals readily act on the given claim (including encouraging others to join in) due to their propensity to resolve the undesired situation (Ilakkuvan et al., 2017; Kim, 2016; Lerner \& Tiedens, 2006; see Berger, 2011; Berger \& Milkman, 2012 for counter-evidence). Compared to those who are anxious, angry individuals are less likely to search for information; even if they do, they are in favor of information that bolsters their beliefs and are against information that undermines their views (MacKuen et al., 2010; Suhay \& Erisen, 2018; Tiedens \& Linton, 2001; Valentino et al., 2008; see de los Santos \& Nabi, 2019 for counter-evidence).

These findings are pertinent in explaining why, in our data, people who felt angry were more vulnerable to misinformation and actively engaged in disseminating false claims about COVID-19. Anger mobilizes and, in turn, angry individuals easily rationalize their act of sharing misinformation by deeming it trustworthy. Actions without deliberation, however, could lead to detrimental consequences such as belief in false cures, which distract people from urgent preventive measures like social distancing. Thus, we argue that managing anger and better engaging the public in the science-based discussions are critical to combat misinformation and minimize its potential harms.

Management of strong action tendencies associated with anger was helpful to South Korea's fight against COVID-19

Many analyses have applauded the South Korean government's transparency and openness in early testing, rigorous contact tracing, and keeping the public informed during COVID-19, as these qualities effectively reduce uncertainty, the primary cause of fear (Lerner \& Keltner, 2000; Smith \& Ellsworth, 1985) associated with the new virus. Here, we are more attentive to how the government guidelines pertain to public anger management. 
We focus on South Korea's decision not to impose a lockdown, but instead to offer very detailed and clear guidelines for communal safeguards, such as wearing a mask, washing hands, eating alone, and using an elbow to cover a cough. The country also held a general election during the pandemic. Despite restrictions, such as having to wear a mask, having to keep a meter distance from others, and having to use hand sanitizer and plastic gloves, the $66 \%$ voter turnout was the highest in 16 years. Given that angry citizens have an urge to unleash their feelings (Groenendyk \& Banks, 2014; Lerner \& Tiedens, 2006; Valentino et al., 2015), following these behavioral directions may elicit a sense of participation in a fight against the pandemic, thus alleviating the public's anger.

The lack of proper public anger management may, in part, explain why stringent measures on COVID19 (e.g., forceful lockdowns) backfire and lead to public protests. Cities around the world that have gone into lockdown show an alarming rise of domestic violence incidents (Graham-Harrison et al., 2020). Frey and colleagues (2020) found that across 111 countries, democratic governments' more lenient approaches were about $20 \%$ more effective in reducing geographic mobility than autocratic governments' stricter ones.

Such patterns are recursive in many social crises, whether economic recessions, natural disasters, or disease outbreaks. Without an adequate release process, anger seldom disappears but transfers to other domains. For example, Vasilopoulos and colleagues (2019) found that anger toward the 2015 Paris terror attack contributed to the rise of far-right parties and policies treating immigrants as a national security threat. Valentino, Wayne, and Oceno (2018) also reported that anger associated with threats to traditional social norms and group hierarchies boosted ethnocentrism and sexism, whereas fear suppressed such tendencies.

To prevent detrimental social behaviors fed by anger, it is crucial to preemptively redirect strong action tendencies of the emotion into a positive direction by nurturing a sense of participation in a fight against the disease. However, how effective such government interventions would be is subject to cultural contexts. The success of South Korea might be rooted in its collectivist cultural traits, which are characterized by conformity, group loyalty, and obedience towards authority (Frey, 2020). In individualistic cultures, the mass public is more suspicious of government interventions.

Science-based conversation during the evolving public health crisis necessitates greater normative responsibilities from partisan media and social media platforms

Despite their government's rapid response to COVID-19, many South Koreans still experienced negative emotions of fear and anger toward the outbreak (Kang, 2020). We found that anger, in particular, contributes to a wider spread of misinformation about COVID-19. There was, however, an ideological difference. Our findings are more nuanced than prior research in that, in our study, conservatives did not report a higher level of anger than their liberal counterparts (Skitka et al., 2006). Instead, angry conservatives more frequently shared misinformation -- mostly on unverified precautionary measures and cures about the new virus -- compared to angry liberals.

The present research is limited in accounting for the difference. Yet, our findings speak to the role of partisan media in times of a public health crisis. Given that their audience is more likely to accept rumors and act on misinformation, conservative media could take greater responsibility in fact-checking. Yet, South Korean conservative media have received warnings from the Korea Communications Standards Commission for releasing news stories riddled with errors about the COVID-19 crisis (Chae, 2020; Lee, 2020).

Relatedly, social media platforms' efforts to flag misinformation and prioritize reliable information are critical. Facebook and Twitter have tweaked their algorithms to promote official accounts and they have clamped down on malicious content about COVID-19. Although these efforts don't completely avert 
the spread of falsehoods online, research has shown that when a claim is fact-checked and found to be false, its virality decreases (Friggeri et al., 2014).

Journalistic interventions, such as fact-checking and content moderation, are indispensable in fostering science-based conversations about preventive measures and cures during the evolving public health crisis. Because of a lack of validated therapeutics or a COVID-19 vaccine, the mitigation strategies will continue to be heavily reliant on behavioral measures, such as personal hygiene, physical distancing, and quarantines (Chinazzi et al., 2020). Since such measures require individuals to change their behaviors according to validated information about the disease, we believe that effectively communicating the most accurate information to the public is critical for minimizing the impact of the pandemic.

The present study used a South Korean sample, and thus its findings should not be overgeneralized to other cultural contexts. However, research using American samples has documented similar patterns of ideological differences: Audiences of conservative media outlets, such as Fox News and Rush Limbaugh, were more prone to be misinformed and believe in conspiracy theories about the COVID-19 pandemic (Hall \& Albarrcin, 2020). This finding suggests that conservative individuals might be more vulnerable to misinformation during the COVID-19 crisis, and thus engaged in a rhetoric of falsehoods, not necessarily due to cultural reasons or the standing of the ruling or the opposition party. Individuals' party identification was included in our analyses as a covariate to rule out these potential confounding effects. Thus, we anticipate that the current research contributes to the further theorization of ideological differences in acceptance and dissemination of misinformation for a future pandemic.

\section{Hypotheses}

Emotion triggers an action (Frijda, 1986). Especially, high-arousal emotions, such as fear and anger, do so more than low-arousal emotions such as sadness (Berger, 2011; Berger \& Milkman, 2012). Given that misinformation sharing requires action, and that fear and anger are the most prominent emotions during the COVID-19 pandemic (Kang, 2020), we propose the following two hypotheses and examine how emotion shapes the diffusion of falsehoods in times of the COVID-19 public health crisis.

Hypothesis 1: Individuals expressing anger are more likely to consider misinformation about COVID19 scientifically credible, and therefore share falsehoods with others more actively. This relationship will vary along ideological lines.

Hypothesis 2: Individuals expressing fear are more likely to consider misinformation about COVID19 scientifically credible, and therefore share falsehoods with others more actively. This relationship will vary along ideological lines.

\section{Findings}

\section{Preliminary observations}

Before the main analyses, we report descriptive statistics and correlations of the considered variables in Table $A$ in the Appendix. This preliminary examination reveals several noteworthy observations. First, anger and fear-both negative and high arousal emotions-are highly correlated. ${ }^{2}$ This relationship is consistent with earlier findings (Vasilopoulos et al., 2019; Weeks, 2015). Second, political ideology is not

${ }^{2} r=.41, p<.001$ 
associated with anger ${ }^{3}$ but with fear. In addition, conservatives experience a greater degree of fear ${ }^{4}$ than liberals. ${ }^{5}$ Third, people living in the Daegu-Gyeongbuk area, which is the most severely impacted region in the nation for COVID-19, ${ }^{6}$ and men, ${ }^{7}$ are more prone to be politically conservative than progressive. Fourth, higher education makes people more critical towards misinformation, ${ }^{8}$ and reluctant to share it. ${ }^{9}$ Lastly, there is a strong positive relationship between beliefs in misinformation and the act of sharing misinformation. ${ }^{10}$

\section{Main analyses}

Our hypotheses test whether anger $(\mathrm{H} 1)$ and fear $(\mathrm{H} 2)$ enhance misinformation sharing by making people believe false claims about COIVD-19 and whether this indirect (or mediated) effect via beliefs in false claims is moderated by political ideology. Figure 2 presents the hypothesized moderated-mediation. According to Muller, Judd, and Yzerbyt (2015), there are three preconditions for a moderated-mediation: (1) no significant interaction effect between an independent variable (i.e., anger or fear) and a moderator (i.e., political ideology) in predicting the dependent variable (i.e., misinformation sharing), (2) a significant interaction effect between the independent variable and the moderator on a mediator (i.e., beliefs in false claims), and (3) a significant main effect of the mediator on the dependent variable. We thus performed a set of regression analyses. The full regression results are summarized in Table 1.

Finding 1: Participants expressing a higher level of anger toward COVID-19 estimated false claims about the virus to be more scientifically credible, resulting in a higher degree of misinformation sharing. This pattern was more evident among conservatives than liberals.

Looking at Model 1 in Table 1, the interaction between anger and ideology has no statistically significant effect on misinformation sharing. ${ }^{11}$ The result indicates that regardless of participants being conservative or liberal, anger has no direct relationship with misinformation sharing. In contrast, Model 2 in Table 1 shows a statistically significant interaction effect between anger and ideology on beliefs in false claims, ${ }^{12}$ as illustrated in Figure 1. Subsequently, Model 3 in Table 1 shows a positive relationship between beliefs in false claims and misinformation sharing. ${ }^{13}$ These two results in concert suggest that conservatives, compared to liberals, contribute more to the spread of misinformation about COVID-19, as they are more likely to believe unverified claims.

${ }^{3} r=-.06, p=.161$

${ }^{4} r=-.13, p=.003$

${ }^{5}$ We would, however, like to note the age effect, in that conservatives, in general, are older than liberals $(r=-.21, p<.001)$.

${ }^{6} r=-.10, p=.023$

${ }^{7} r=-.16, p<.001$

${ }^{8} r=-.14, p=.002$

${ }^{9} r=-.14, p=.002$

${ }^{10} r=.80, p<.001$

${ }^{11} b=-.11, S E=.07, p=.106$

${ }^{12} b=-.12, S E=.06, p=.036$

${ }^{13} b=.87, S E=.03, p<.001$ 
Table 1. Regression results: The indirect effects of negative emotions and political ideology on misinformation sharing via beliefs in false claims about COVID-19 $(N=513)$.

\begin{tabular}{|c|c|c|c|c|c|c|}
\hline & \multicolumn{2}{|c|}{ Model 1} & \multicolumn{2}{|c|}{ Model 2} & \multicolumn{2}{|c|}{ Model 3} \\
\hline & \multicolumn{2}{|c|}{$\begin{array}{l}\text { Misinformation } \\
\text { sharing }\end{array}$} & \multicolumn{2}{|c|}{$\begin{array}{c}\text { Beliefs in false } \\
\text { claims }\end{array}$} & \multicolumn{2}{|c|}{$\begin{array}{l}\text { Misinformation } \\
\text { sharing }\end{array}$} \\
\hline & $b$ & $S E$ & $b$ & $S E$ & $b$ & $S E$ \\
\hline Constant & .71 & 1.47 & 1.14 & 1.30 & .01 & .93 \\
\hline Anger & .53 & .28 & $.58 *$ & .25 & -.02 & .18 \\
\hline Fear & .03 & .33 & -.02 & .29 & .02 & .21 \\
\hline Ideology (7 = extremely liberal) & .38 & .31 & .49 & .27 & -.03 & .20 \\
\hline Anger $\times$ Ideology & -.11 & .07 & $-.12 *$ & .06 & .01 & .04 \\
\hline Fear × Ideology & .02 & .08 & .01 & .07 & .004 & .05 \\
\hline Age & $.02 * *$ & .01 & $.02 * *$ & .01 & .002 & .004 \\
\hline Region (1 = Daegu-Gyeongbuk) & -.26 & .23 & -.18 & .20 & -.24 & .14 \\
\hline Education level & $-.16 * *$ & .05 & $-.15 * *$ & .05 & -.03 & .03 \\
\hline Household income & .05 & .03 & .03 & .03 & .02 & .02 \\
\hline Gender ( 1 = women $)$ & -.07 & .21 & -.17 & .19 & .08 & .13 \\
\hline PartyID (4= strong supporters of MPK) & -.09 & .07 & $-.18 * *$ & .06 & -.01 & .04 \\
\hline Beliefs in false claims & & & & & $.87 * * *$ & .03 \\
\hline$R^{2}$ & \multicolumn{2}{|c|}{.065} & \multicolumn{2}{|c|}{.088} & \multicolumn{2}{|c|}{.629} \\
\hline
\end{tabular}

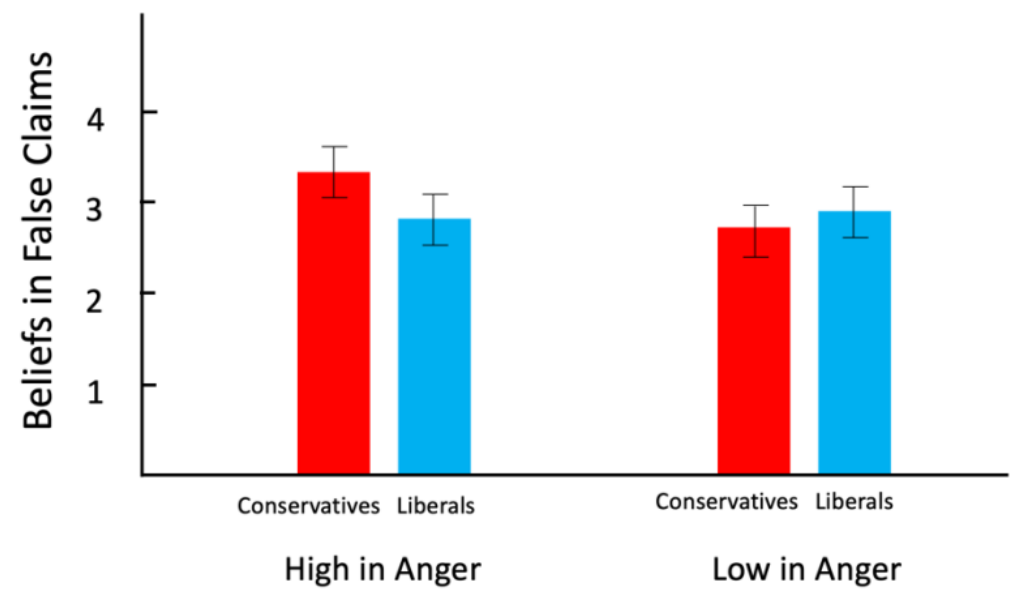

Figure 1. The interaction effect of anger and political ideology on beliefs in false claims about COVID-19.

This cognitive mechanism behind misinformation sharing is presented in Figure 2 . This indirect relationship is further confirmed with a bootstrap re-sampling analysis. ${ }^{14}$ For the analyses, we used Hayes' (2017) PROCESSS macro and computed the 95\% bias-corrected confidence intervals based on 10,000 samples.

\footnotetext{
${ }^{14}$ indirect effect $=-.11$, bootSE $=.04,95 \%$ bias-corrected CI [-.1965 to -.0235$]$
} 


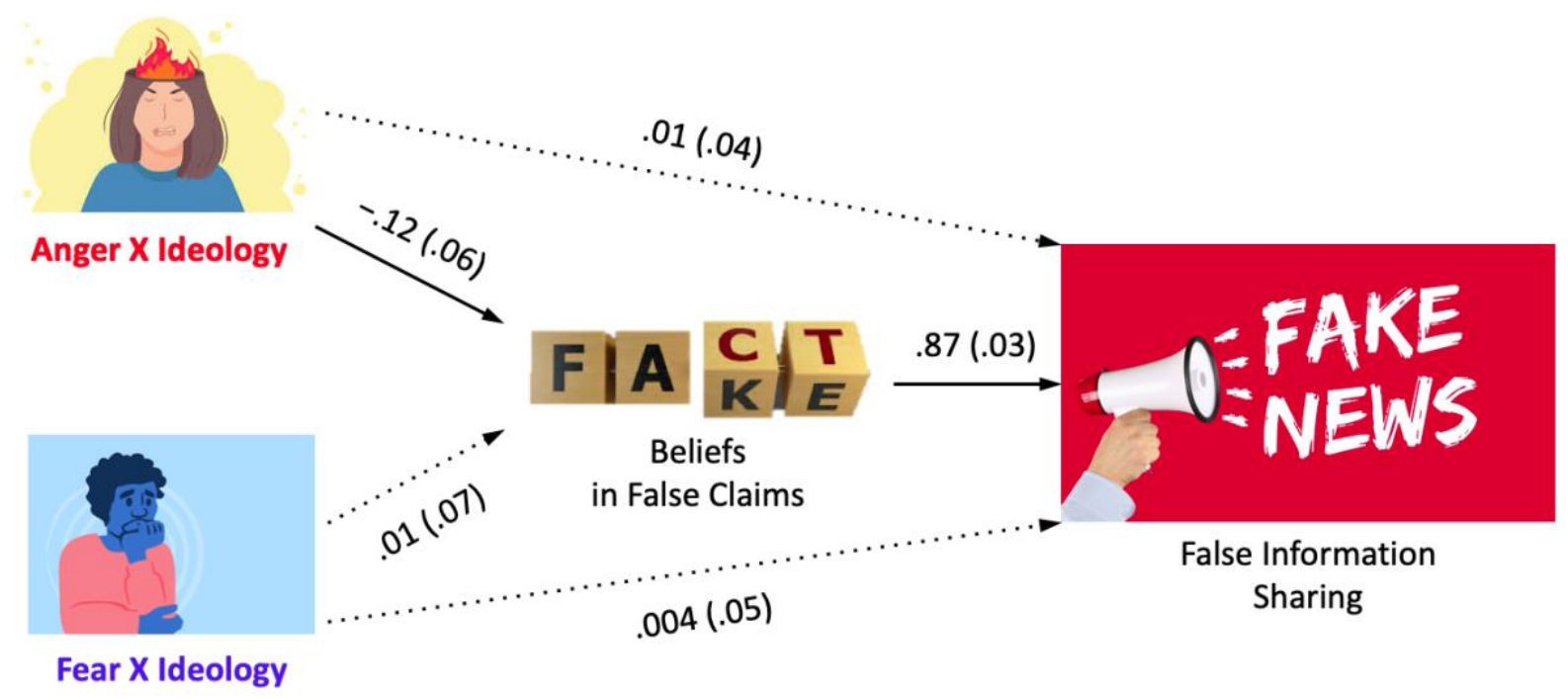

Figure 2. The indirect effect of anger and fear moderated by political ideology on misinformation sharing via beliefs in false claims. Estimates are reported as unstandardized (standard error). Solid lines indicate significant regression coefficients at the alpha level of .05. Dotted lines indicate insignificant regression coefficients.

Finding 2: Participants who expressed a higher level of fear toward COVID-19 did not necessarily consider false claims about COVID-19 more scientifically credible than usual. No difference was found between conservatives and liberals. Accordingly, no indirect effect of fear and political ideology on misinformation sharing was found via beliefs in false claims.

Looking at Model 1 in Table 1, the interaction between fear and ideology has no statistically significant effect on misinformation sharing. ${ }^{15}$ The result indicates that regardless of participants being conservative or liberal, fear has no direct influence on misinformation sharing. Next, Model 2 in Table 1 shows no statistically significant effect of fear on beliefs in false claims as a function of ideology. ${ }^{16}$ There is no ideological difference in disseminating falsehoods. This insignificant indirect effect is graphed in Figure 2 and confirmed with a bootstrap re-sampling analyses. ${ }^{17}$

\section{Methods}

\section{Participants}

We fielded a nationwide online survey in South Korea $(N=513)$ between April $9^{\text {th }}$ and $13^{\text {th }}$. The Korea Broadcasting System (KBS) Public Media Institute ${ }^{18}$ recruited study samples from an online panel of approximately 20,000 respondents. Consistent with the nation's population statistics based on residence

\footnotetext{
${ }^{15} b=.01, S E=.08, p=.845$

${ }^{16} b=.01, S E=.07, p=.845$

17 indirect effect $=.01$, bootSE $=.06,95 \%$ bias-corrected CI [ -.0973 to .1269$]$

${ }^{18} \mathrm{See}$ http://office.kbs.co.kr/bri/
} 
registration in March 2020, ${ }^{19}$ our sample was matched to be the same proportions of individuals in terms of key Korean demographics, including gender, age, and region. Given that Daegu-Gyeongbuk is South Korea's hardest-hit region from the COVID-19 pandemic, we purposefully recruited $30 \%$ of participants from this area. From the sample selected, 50.3\% were women, 36.6\% resided in Seoul and Gyeonggi (i.e., the greater Seoul area), and $64.5 \%$ had some college education or higher. The average age was 47 years $(S D=16.65$ ) with a range of 18 to 94 . The average household income was between $\$ 40,010,000$ (about $\$ 34,000$ ) and $\$ 50,000,000$ (about $\$ 42,000$ ). The margin of error for total respondents was $\pm 4.3 \% p$ at the $95 \%$ confidence level. The response rate was $8.92 \%$.

\section{Measures}

Participants responded to the questions in the following order:

Emotions: We measured participants' feelings about the COVID-19 outbreak. Using 6-point Likert scales ( 1 = strongly disagree, 6 = strongly agree), participants indicated to what extent they agree or disagree with the following statements presented in a random order: (1) I am angry, and (2) I am afraid. ${ }^{20}$

Beliefs in false claims: To assess participants' beliefs in false claims about COVID-19, we identified twelve false claims from a list of over 200 fact-checked rumors from China and South Korea. These COVID-19 rumors came from DXY.cn, a Chinese online community for physicians and health care professionals. This site hosted a comprehensive list of rumors that were shared on Chinese social media. After removing redundant content, any lockdown-related claims, or politically oriented content, we identified twelve claims that also propagated in South Korea. All claims had been fact-checked and identified as false either by the World Health Organization (WHO), the Centers for Disease Control and Prevention (CDC) in the US, and/or the Korea Centers for Disease Control and Prevention (KCDC). The claims included:

- "Gargling with salt water can eliminate the virus";

- "hair dryers can kill the virus";

- "drinking hot water or hot tea can reduce the chances of getting infected with COVID-19";

- "garlic can prevent infection";

- "only certain age groups, races, or ethnicities are vulnerable to the virus";

- "antibiotics or flu vaccines can prevent the disease"; and

- "you can test yourself for COVID-19 by holding your breath for 10 seconds" (see Table 2 for all twelve claims).

Participants indicated whether they found each of the false claims "scientifically credible" or not with two answer choices $(0=$ No, $1=Y e s)$. The items were presented in a random order. We computed the measure of beliefs in false information by summing the "Yes" responses (Cronbach's alpha $=.70$ ).

Misinformation sharing: Related to the twelve misinformation about COVID-19, participants were next asked whether they would share each of the claims with others or not with two answer choices $(0=$ No,

\footnotetext{
${ }^{19} \mathrm{See}$ http://kosis.kr/eng/index/index.do

${ }^{20}$ To measure anger, we used two-items (i.e., I am angry, and I am disgusted). So did for measuring anxiety (i.e., I am afraid, and I am worried). However, given the low measurement reliabilities of anger (Spearman-Brown coefficient $=.526$ ) and anxiety (Spearman-Brown coefficient $=.611$ ), we used a single measure for each emotion.
} 
1 = Yes). The items were presented in a random order and summed to create the measure of misinformation sharing (Cronbach's alpha $=.77)$.

Political ideology: Participants indicated their political ideology on a 7-point scale $(1=$ extremely conservative, $4=$ moderate, 7 = extremely liberal).

Party identification: Party identification was assessed using a standard branching measure. Participants first indicated which party they supported by selecting one answer from a list of political parties in South Korea. Those identifying themselves as supporters of the Minjoo Party of Korea (MPK, the progressive ruling party) and the United Future Party (UFP, the conservative, opposing party) were then asked to indicate to what extent they supported their parties on a 3-point scale $(1=$ somewhat support, $3=$ strongly support). Those identifying themselves as independents or supporters of some other party were asked whether they think of themselves as closer to supporters of MPK, supporters of UFP, or neither. For analyses, these measures were recoded into a single measure ranging from -4 (strong supporters of UFP) to +4 (strong supporters of MPK). Pure independents were coded as 0 ; UFP-leaners were coded as -1 and MPK-leaners were coded as +1 .

Gender: Participants indicated their gender with two answer choices $(0=m e n, 1=$ women $)$. Age. Participants were asked to write down their age.

Region: Participants indicated their residence area with multiple choices of (1) Seoul, (2) Busan, (3) Daegu, (4) Incheon, (5) Gwangju, (6) Daejeon, (7) Ulsan, (8) Gyeonggi, (9) Gangwon, (10) Chungbuk, (11) Chungnam, (12) Jeonbuk, (13) Jeonnam, (14) Gyeongbuk, (15) Gyeongnam, (16) Jeju, and (17) Sejong. For our analyses, the responses were recoded as 1 (Daegu-Gyeongbuk, COVID-19 hotspots in South Korea) and 0 (the other areas).

Education level: Participants indicated their level of education with multiple choices of (1) No elementary school diploma, (2) Elementary school graduates, (3) No middle school diploma, (4) Middle school graduates, (5) No high school diploma, (6) High school graduates, (7) Some college, (8) Professional college degrees, (9) 4-year university students, (10) Bachelor's degrees, (11) Graduate students, and (12) Master's degrees or higher.

Household income: Participants indicated their household income with multiple choices of (1) Less than $\$ 10,000,000$, (2) Between $\$ 10,010,000$ and $\$ 20,000,000$, (3) Between $\$ 20,010,000$ and $\$ 30,000,000$, (4) Between $\$ 30,010,000$ and $\$ 40,000,000$, (5) Between $\$ 40,010,000$ and $\$ 50,000,000$, (6) Between $\$ 50,010,000$ and $\$ 60,000,000$, (7) Between $\$ 60,010,000$ and $\$ 70,000,000$, (8) Between $\$ 70,010,000$ and $\$ 80,000,000$, (9) Between $\$ 80,010,000$ and $\$ 90,000,000,(10)$ Between $\$ 90,010,000$ and $\$ 100,000,000$, and (11) More than $\$ 100,000,000$. 
Table 2. Twelve false claims about COVID-19 $(N=513)$.

\begin{tabular}{lcc}
\hline & $\begin{array}{c}\text { Beliefs in false } \\
\text { claims }\end{array}$ & $\begin{array}{c}\text { Misinformation } \\
\text { sharing }\end{array}$ \\
\hline Even if completely cured, COVID-19 patients suffer from & $63.7 \%$ & $53.1 \%$ \\
life-long lung damage. & $31.6 \%$ & $25.3 \%$ \\
A runny nose is a symptom of cold, not COVID-19. & $6.2 \%$ & $7.6 \%$ \\
Hair dryers can kill the virus. & $2.6 \%$ & $3.7 \%$ \\
Drinking alcohol can kill the virus. & $68.0 \%$ & $56.2 \%$ \\
Only certain age groups, races, or ethnicities are vulnerable & & \\
to the virus. & $27.2 \%$ & $22.3 \%$ \\
Antibiotics or flu vaccines can prevent the disease. & $8.7 \%$ & $9.4 \%$ \\
You can test yourself for COVID-19 by holding your breath & & $17.5 \%$ \\
for 10 seconds. & $19.9 \%$ & $7.7 \%$ \\
Garlic can prevent infection. & $7.3 \%$ & $15.7 \%$ \\
Gargling with salt water can eliminate the virus. & $19.0 \%$ & $2.4 \%$ \\
The virus can penetrate into the body through contact. & $4.2 \%$ & $31.1 \%$ \\
Smoking can kill the virus. & $32.6 \%$ & \\
Drinking hot water or hot tea can reduce the chances of & & \\
getting infected with COVID-19. & & \\
\hline Note: Results are the percentage of "Yes" responses to the questions of "Beliefs in false claims" and \\
"Misinformation sharing."
\end{tabular}

\section{Bibliography}

Berger, J. (2011). Arousal increases social transmission of information. Psychological Science, 22(7), 891893. https://doi.org/10.1177/0956797611413294

Berger, J., \& Milkman, K. L. (2012). What makes online content viral? Journal of Marketing Research, 49(2), 192-205. https://doi.org/10.1509/jmr.10.0353

Carver, C. S., \& Harmon-Jones, E. (2009). Anger is an approach-related affect: Evidence and implications. Psychological Bulletin, 135(2), 183-204. https://doi.org/10.1037/a0013965

Chae, J. (2020, April 25). Coronavirus breaking news ... False reporting. Hankuk II-bo. https://www.hankookilbo.com/News/Read/202004231827323119

Chinazzi, M., Davis, J. T., Ajelli, M., Gioannini, C., Litvinova, M., Merler, S., Pastore y Piontti, A., Mu, K., Rossi, L., Sun, K., Viboud, C., Xiong, X., Yu, H., Halloran, M. E., Longini, I. M., \& Vespignani, A. (2020). The effect of travel restrictions on the spread of the 2019 novel coronavirus (COVID-19) outbreak. Science, 368(6489), 395-400. https://doi.org/10.1126/science.aba9757

de los Santos, T. M., \& Nabi, R. L. (2019). Emotionally charged: Exploring the role of emotion in online news information seeking and processing. Journal of Broadcasting \& Electronic Media, 63(1), 39-58. https://doi.org/10.1080/08838151.2019.1566861

Frey, C. B., Chen, C. C., \& Presidente, G. (2020). Democracy, culture, and contagion: Political regimes and countries responsiveness to Covid-19.

https://www.oxfordmartin.ox.ac.uk/downloads/academic/Democracy-Culture-andContagion May13.pdf

Frey, C. B. (2020, May 26). Democracies have proven they have the edge in coping with this crisis. Financial Times. https://www.ft.com/content/5d08522e-99b2-11ea-871b-edeb99a20c6e 
Friggeri, A., Adamic, L., Eckles, D., \& Cheng, J. (2014). Rumor cascade. Proceedings of the Eighth International AAAI Conference on Weblogs and Social Media. https://www.aaai.org/ocs/index.php/ICWSM/ICWSM14/paper/viewFile/8122/8110

Frijda, N. H. (1986). The emotions. Cambridge University Press.

Graham-Harrison, E., Giuffrida, A., Smith, H., \& Ford, L. (2020, March 28). Lockdowns around the world bring rise in domestic violence. The Guardian.

https://www.theguardian.com/society/2020/mar/28/lockdowns-world-rise-domestic-violence

Groenendyk, E. W., \& Banks, A. J. (2014). Emotional rescue: How affect helps partisans overcome collective action problems. Political Psychology, 35(3), 359-378. https://doi.org/10.1111/pops.12045

Hall, K. J., \& Albarracín, D. (2020). The relation between media consumption and misinformation at the outset of the SARS-CoV-2 pandemic in the US. Harvard Kennedy School (HKS) Misinformation Review 1(3). https://doi.org/10.37016/mr-2020-012

Hayes, A. F. (2017). Introduction to mediation, moderation, and conditional process analysis: A regression-based approach ( $2^{\text {nd }}$ ed.). The Guilford Press.

Hong, K. W., \& Lee, J. T. (2010). A study on the relations of ideological topology and psychological bases in South Korean adults. The Korean Journal of Social and Personal Psychology. 24(2), 1-25. https://doi.org/10.21193/kjspp.2010.24.2.001

llakkuvan, V., Turner, M. M., Cantrell, J., Hair, E., \& Vallone, D. (2017). The relationship between advertising-induced anger and self-efficacy on persuasive outcomes: A test of the anger activism model using the truth campaign. Family \& Community Health, 40(1), 72-80. https://doi.org/10.1097/fch.0000000000000126

Kang, E. J. (2020, April 3). Six-in-ten says, "Daily life near a standstill" ...'Feeling angry' has tripled. Donga II-bo. https://www.donga.com/news/Society/article/all/20200304/100008952/1

Kim, N. (2016). Beyond rationality. Communication Research, 43(1), 3-24. https://doi.org/10.1177/0093650213510943

Lee, H. (2020, May 11). KCSC warned TV Chosun for its false reporting of health center refusing to test for Covid-19. Yonhap. https://www.yna.co.kr/view/AKR20200511150300017

Lerner, J. S., Gonzalez, R. M., Small, D. A., \& Fischhoff, B. (2003). Effects of fear and anger on perceived risks of terrorism: A national field experiment. Psychological Science, 14(2), 144-150. https://doi.org/10.1111/1467-9280.01433

Lerner, J. S., \& Keltner, D. (2000). Beyond valence: Toward a model of emotion-specific influences on judgment and choice. Cognition and Emotion, 14, 473-493.

Lerner, J. S., \& Keltner, D. (2001). Fear, anger, and risk. Journal of Personality and Social Psychology, 81(1), 146-159. https://doi.org/10.1037/0022-3514.81.1.146

Lerner, J. S., \& Tiedens, L. Z. (2006). Portrait of the angry decision maker: How appraisal tendencies shape anger's influence on cognition. Journal of Behavioral Decision Making, 19(2), 115-137. https://doi.org/10.1002/bdm.515

MacKuen, M., Wolak, J., Keele, L., \& Marcus, G. E. (2010). Civic engagements: Resolute partisanship or reflective deliberation. American Journal of Political Science, 54(2), 440-458. https://doi.org/10.1111/j.1540-5907.2010.00440.x

Miller, D. A., Cronin, T., Garcia, A. L., \& Branscombe, N. R. (2009). The relative impact of anger and efficacy on collective action is affected by feelings of fear. Group Processes \& Intergroup Relations, 12(4), 445-462. https://doi.org/10.1177\%2F1368430209105046

Muller., D., Judd, C. M., \& Yzerbyt, V. Y. (2005). When moderation is mediated and mediation is moderated. Journal of Personality and Social Psychology, 89(6), 852-863. https://doi.org/10.1037/0022-3514.89.6.852 
Skitka, L. J., Bauman, C. W., Aramovich, N. P., \& Morgan, G. S. (2006). Confrontational and preventative policy responses to terrorism: Anger wants a fight and fear wants "them" to go away. Basic and Applied Social Psychology, 28(4), 375-384. https://doi.org/10.1207/s15324834basp2804 11

Smith, C.A., \& Ellsworth, P.C. (1985). Patterns of cognitive appraisal in emotion. Journal of Personality and Social Psychology, 48, 813-838. https://doi.org/10.1037/0022-3514.48.4.813

Suhay, E., \& Erisen, C. (2018). The role of anger in the biased assimilation of political information. Political Psychology, 39(4), 793-810. https://doi.org/10.1111/pops.12463

Tiedens, L. Z., \& Linton, S. (2001). Judgment under emotional certainty and uncertainty: The effects of specific emotions on information processing. Journal of Personality and Social Psychology, 81(6), 973-988. https://doi.org/10.1037/0022-3514.81.6.973

Turner, M. M., Rimal, R. N., Morrison, D., \& Kim, H. (2006). The role of anxiety in seeking and retaining risk information: Testing the risk perception attitude framework in two studies. Human Communication Research, 32(2), 130-156. https://doi.org/10.1111/j.1468-2958.2006.00006.x

Valentino, N. A., Brader, T., Groenendyk, E. W., Gregorowicz, K., \& Hutchings, V. L. (2015). Election night's alright for fighting: The role of emotions in political participation. The Journal of Politics, 73(1),156-170. https://doi.org/10.1017/S0022381610000939

Valentino, N. A., Hutchings, V. L., Banks, A. J., \& Davis, A. K. (2008). Is a worried citizen a good citizen? Emotions, political information seeking, and learning via the Internet. Political Psychology. https://doi.org/10.1111/j.1467-9221.2008.00625.x

Valentino, N. A., Wayne, C., \& Oceno, M. (2018). Mobilizing sexism: The interaction of emotion and gender attitudes in the 2016 US presidential election. Public Opinion Quarterly, 82(S1), 799821. https://doi.org/10.1093/poq/nfy003

Vasilopoulos, P., Marcus, G. E., Valentino, N. A., \& Foucault, M. (2019). Fear, anger, and voting for the far right: Evidence from the November 13, 2015 Paris Terror Attacks. Political Psychology, 40(4), 679-704. https://doi.org/10.1111/pops.12513

Vosoughi, S., Roy, D., \& Aral, S. (2018). The spread of true and false news online. Science, 359(6380), 1146-1151. https://doi.org/10.1126/science.aap9559

Weeks, B. E. (2015). Emotions, partisanship, and misperceptions: How anger and anxiety moderate the effect of partisan bias on susceptibility to political misinformation. Journal of Communication, 65(4), 699-719. https://doi.org/10.1111/jcom.12164

Zhao, X., \& Cai, X. (2009). The role of risk, efficacy, and anxiety in smokers' cancer information seeking. Health Communication, 24(3), 259-269. https://doi.org/10.1080/10410230902805932 


\section{Acknowledgement}

We thank Richard Moore for his feedback on this article.

\section{Funding}

This work was partly supported by a research grant for new scholars from the Korean Society for Journalism and Communication Studies (KSJCS) and the Korean Broadcasting System (KBS) in 2020. J. Han was supported by the National Research Foundation of Korea (NRF-2020S1A5B5A16083698). M. Cha was supported by the Institute for Basic Science (IBS-R029-C2). W. Lee was supported by the National Research Foundation of Korea (NRF-2016S1A3A2925033).

\section{Competing interests}

The author(s) declared no potential conflicts of interest with respect to the research, authorship, and/or publication of this article.

\section{Ethics}

The institutional review board at KAIST approved the research protocol. Human subjects gave informed consent before participating and were debriefed at the end of the study.

\section{Copyright}

This is an open access article distributed under the terms of the Creative Commons Attribution License, which permits unrestricted use, distribution, and reproduction in any medium, provided that the original author and source are properly credited.

\section{Data availability}

All materials needed to replicate this study are available via the Harvard Dataverse: https://doi.org/10.7910/DVN/TINOSK 


\section{Appendix}

Table A. Descriptive statistics and intercorrelations $(N=513)$

\begin{tabular}{|c|c|c|c|c|c|c|c|c|c|c|c|c|c|}
\hline & \multirow{2}{*}{ Range } & \multicolumn{2}{|c|}{$\begin{array}{l}\text { Descriptive } \\
\text { statistics }\end{array}$} & \multicolumn{10}{|c|}{ Correlations } \\
\hline & & $M$ & $S D$ & 1 & 2 & 3 & 4 & 5 & 6 & 7 & 8 & 9 & 10 \\
\hline 1. Ideology & 1 to 7 & 4.18 & 1.17 & - & & & & & & & & & \\
\hline 2. Anger & 1 to 6 & 3.91 & 1.42 & -.06 & - & & & & & & & & \\
\hline 3. Fear & 1 to 6 & 3.92 & 1.31 & $-.13^{* *}$ & $.41^{* * *}$ & - & & & & & & & \\
\hline 4. Beliefs in false claims & 0 to 12 & 2.91 & 2.07 & -.08 & $.10^{*}$ & $.11^{*}$ & - & & & & & & \\
\hline 5. Misinformation sharing & 0 to 12 & 2.52 & 2.30 & -.07 & $.10^{*}$ & $.10^{*}$ & $.80^{* * *}$ & - & & & & & \\
\hline 6. Age & 18 to 94 & 47.47 & 15.65 & $-.21^{* * *}$ & .06 & $.13^{* *}$ & $.17^{* * *}$ & $.15^{* *}$ & - & & & & \\
\hline 7. Region ( 1 = Daegu-Gyeongbuk) & 0 to 1 & .27 & .44 & $-.10^{*}$ & .04 & .07 & .001 & -.03 & .02 & - & & & \\
\hline 8. Education level & 2 to 12 & 9.08 & 2.05 & .03 & -.04 & -.01 & $-.14^{* *}$ & $-.14^{* *}$ & $-.10^{*}$ & -.08 & - & & \\
\hline 9. Household income & 1 to 12 & 5.32 & 3.09 & .05 & -.06 & -.08 & -.004 & .01 & $-.18^{* * *}$ & .01 & $.17^{* * *}$ & - & \\
\hline 10. Gender ( $1=$ women $)$ & 0 to 1 & .50 & .50 & $-.16^{* * *}$ & $-.14^{* * *}$ & $-.11^{* *}$ & -.08 & -.05 & .01 & .004 & $.17^{* * *}$ & -.05 & - \\
\hline 11. Party identification & -4 to 4 & .58 & 2.06 & $.65^{* * *}$ & $-.12^{*}$ & $-.22^{* * *}$ & $-.14^{* *}$ & $-.11^{*}$ & $-.23^{* * *}$ & -.06 & .01 & .05 & -.08 \\
\hline
\end{tabular}

$* p<.05, * * p<.01, * * * p<.001$. 